\title{
Delayed ventricular septal rupture complicating anterior wall myocardial infarction
}

\author{
Rajdip Dulai, Aye Hline, Mahvesh Rana Javaid, Javed Akhtar
}

Department of Cardiology, Barking, Havering and Redbridge University Hospitals NHS Trust, Romford, Essex, UK

\section{Correspondence to}

Dr Rajdip Dulai,

rajdip.dulai@bhrhospitals. nhs.uk

Accepted 14 November 2016

\section{SUMMARY}

A 59-year-old woman was admitted to our hospital with acute pulmonary oedema and cardiogenic shock 35 days after anterior ST elevation myocardial infarction. She developed a new loud pan systolic murmur. Echocardiography revealed a ventricular septal rupture with a significant left to right shunt. She was immediately transferred to the local cardiothoracic unit where she underwent a successful ventricular septal defect (VSD) repair. Ventricular septal rupture often presents within the first 24 hours of acute myocardial infarction and is rare thereafter. It carries a poor mortality (41-80\%) even when recognised. Timely recognition of this life-threatening complication can help reduce the resultant morbidity and mortality. Doctors should be aware that this well-recognised complication may present unusually late as in this case.

\section{BACKGROUND}

We wrote this case to highlight that ventricular septal rupture can present extremely late following an ST elevation myocardial infarction. It is important to be vigilant of this potentially lethal complication, and a careful clinical examination is crucial for improving patient outcomes. Despite significant advances in the diagnosis of myocardial infarction and early management with primary percutaneous coronary intervention (PCI), ventricular septal rupture can develop from hours to weeks after treatment.

\section{CASE PRESENTATION}

A 59-year-old woman with type 2 diabetes initially presented to our institution generally unwell with symptoms of nausea and vomiting for 4 days. She denied any chest pain or shortness of breath. She was drowsy and confused. On examination, her chest was clear to auscultation, and her heart sounds were normal with no audible murmur. She was found to be in diabetic ketoacidosis secondary to sepsis from a urinary tract infection. As part of the routine clinical workup, a 12-lead ECG was recorded (figure 1). The ECG revealed a sinus tachycardia with a right bundle branch block pattern and ST elevation in the anterior and lateral leads. Q waves were present in leads V2-V4 and inferiorly. The ECG findings were suggestive of a late presentation of STEMI with possible ventricular aneurysm. Echocardiography revealed aneurysmal formation with akinetic walls from mid to apical septum, anterior and anteroseptal walls (figures 2 and 3 and video 1). Ejection fraction was estimated to be $20 \%$. Mild mitral regurgitation was noted.

The admitting team diagnosed a delayed presentation of ST elevation myocardial infarction, and subsequently the case was discussed with the local cardiothoracic centre for consideration of emergency revascularisation. However, it was felt that the patient did not need to undergo emergency revascularisation as this was a delayed presentation of STEMI as evidenced by the well-formed Q waves plus ventricular aneurysm on the ECG and echocardiogram. Ventricular aneurysm typically results from expansion of infarcted myocardial tissue within the first 2-14 days post-myocardial infarction. ${ }^{1}$ In addition, the patient did not have ongoing ischaemia as evidenced by the
To cite: Dulai $R$, Hline $A$, Javaid MR, et al. BMJ Case Rep Published online: [please include Day Month Year] doi:10.1136/bcr-2016215523

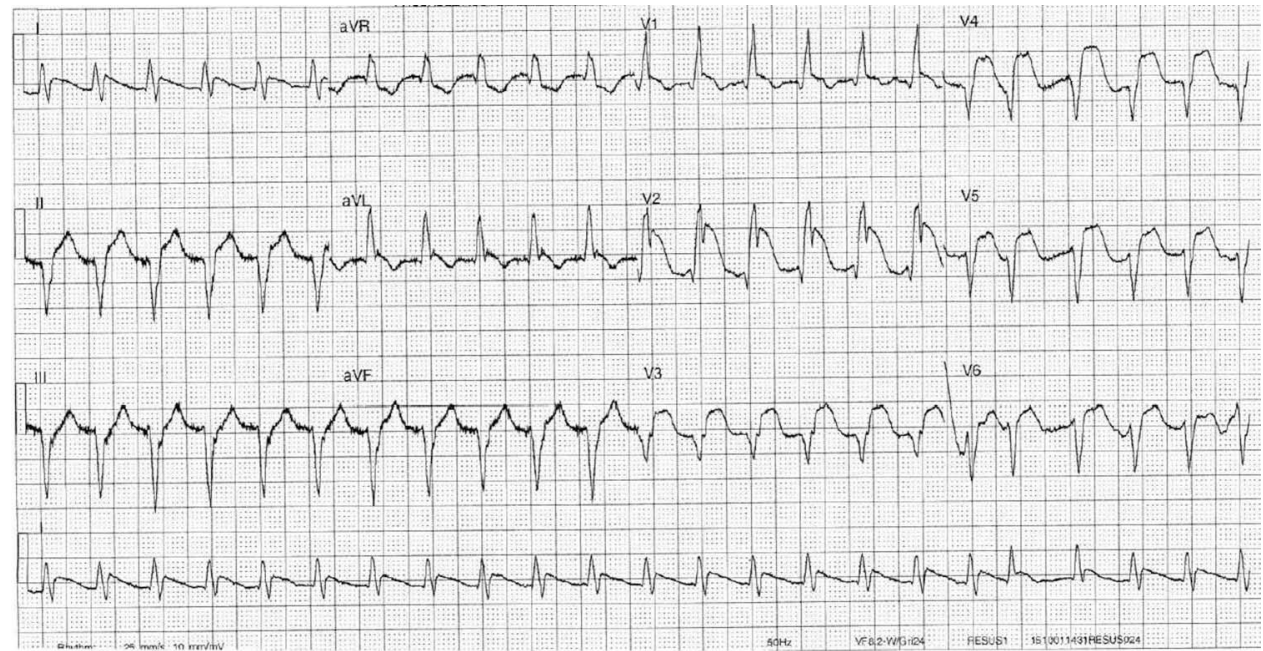

Figure 1 Initial ECG suggestive of late presentation of STEMI with possible ventricular aneurysm. 


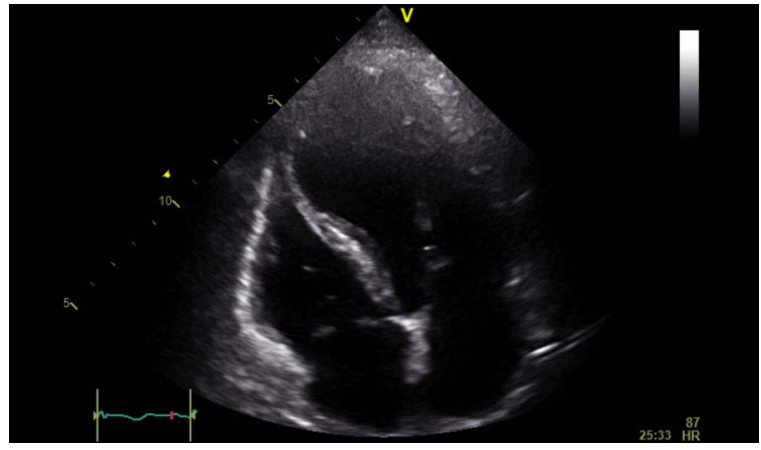

Figure 2 Initial echocardiography revealing aneurysmal formation with akinetic walls from mid to apical septum, anterior and anteroseptal walls without colour flow Doppler (apical four-chamber view).

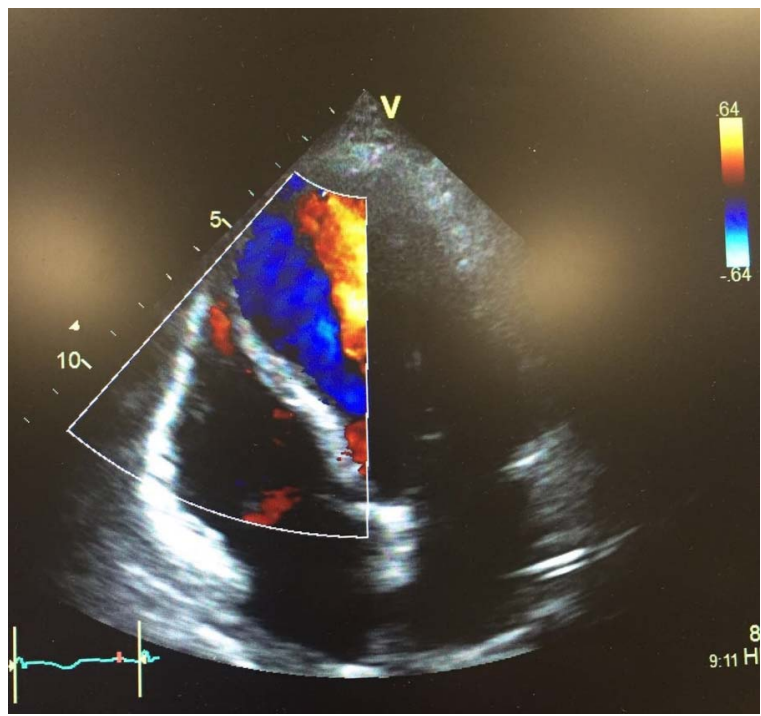

Figure 3 Initial echocardiography revealing aneurysmal formation with akinetic walls from mid to apical septum, anterior and anteroseptal walls with colour flow Doppler (apical four-chamber view).

non-dynamic changes on serial ECGs. She was therefore treated medically with Fondaparinux, Aspirin and Clopidogrel with a plan for angiography once the sepsis and diabetic ketoacidosis had resolved.

She was admitted to the high-dependency unit where she was resuscitated with intravenous fluids and antibiotics. She was subsequently stepped down to the coronary care unit but then developed an upper gastrointestinal bleed necessitating blood transfusion and discontinuation of her antiplatelet therapy. An oesophago-gastroduodenoscopy showed no bleeding source but mild diffuse duodenitis. She was subsequently restarted on aspirin only with no further episodes of bleeding. This led to a delay in her coronary angiogram. She underwent a coronary angiogram 10 days after initial presentation, which showed multiple sequential stenoses in the left anterior descending artery (LAD) (figures 4 and 5 plus video 2). Spontaneous coronary artery dissection was considered; however, given the clinical context, it was felt that most likely the angiogram findings reflected multiple stenoses in the LAD. Percutaneous stent insertion was considered unsuitable due to the nature of the disease and evidence of completed anterior infarction on echocardiography.

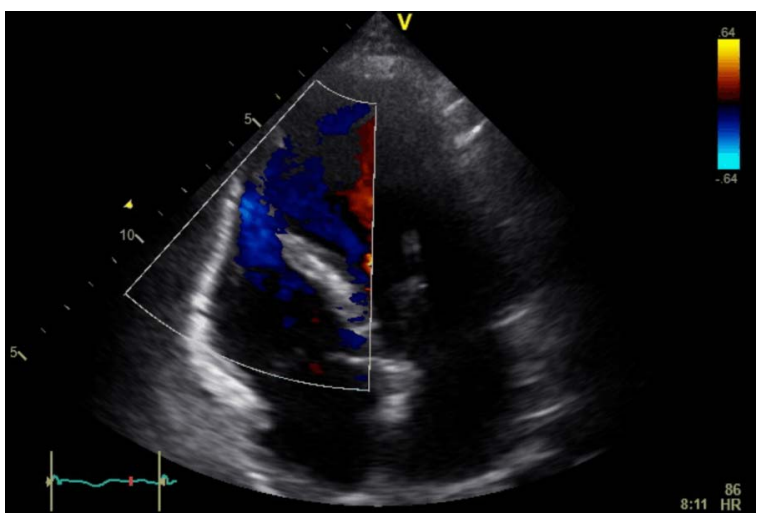

Video 1 Initial echocardiography revealing aneurysmal formation with akinetic walls from mid to apical septum, anterior and anteroseptal walls with colour flow Doppler showing intact septum (apical four-chamber view).

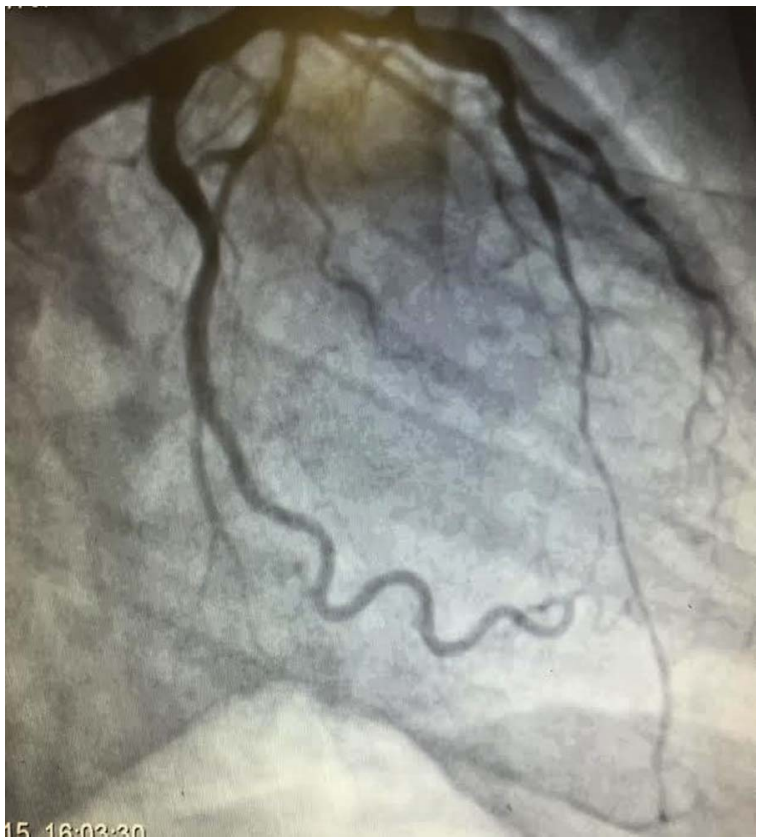

Figure 4 Coronary angiogram showing multiple sequential stenoses in the left anterior descending artery.

She was subsequently discharged from hospital 25 days after admission following a complicated recovery including cellulitis of the hand and rehabilitation. On discharge, she was well with minimal heart failure symptoms (NYHA classification 1). She was referred for an outpatient cardiac MRI to assess viability of the LAD territory.

Ten days later, she was readmitted to our hospital with acute shortness of breath and bilateral leg swelling. The symptoms started with new onset orthopnoea over the preceding week. On general examination, she was hypotensive with a blood pressure of 77/62, and her heart rate was $90 \mathrm{bpm}$. She was tachypnoeic with a respiratory rate of $28 / \mathrm{min}$, and her oxygen saturation was $98 \%$ on 21 oxygen. She had bibasal crepitations and a new grade 5 pan systolic murmur.

The initial diagnosis made by the admitting team was acute pulmonary oedema secondary to an ischaemic cardiomyopathy and mitral regurgitation. She was admitted to the coronary care 


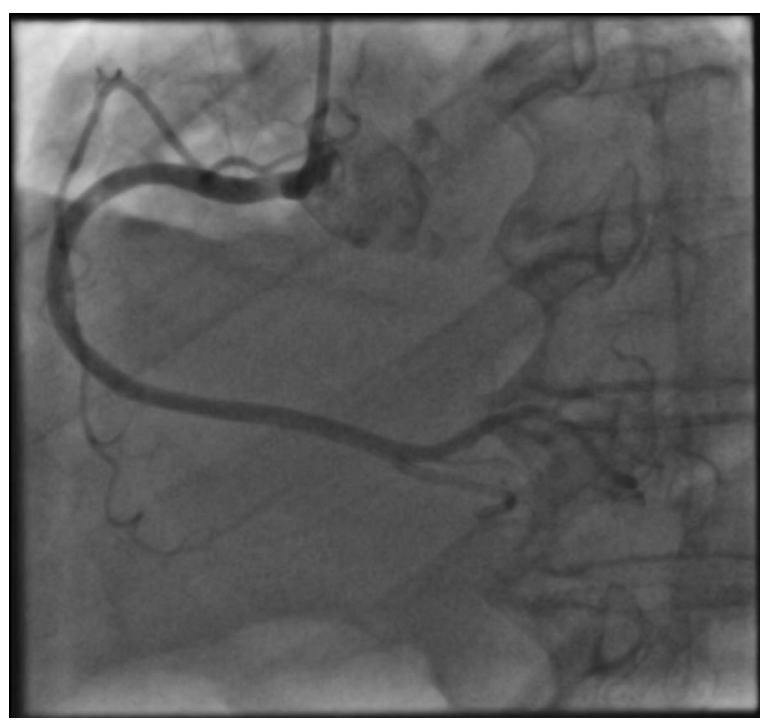

Figure 5 Coronary angiogram showing patent right coronary artery.

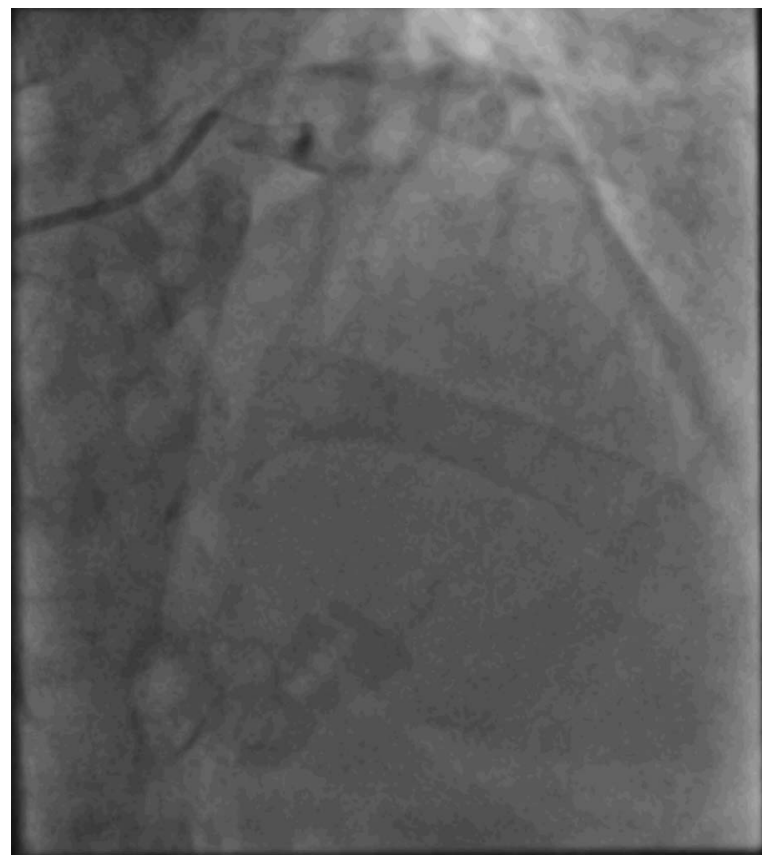

Video 2 Angiography of the left coronary system showing multiple sequential stenoses in the left anterior descending artery.

unit for diuresis where Dobutamine was initiated. In light of the new clinical findings, an emergency echocardiogram was performed.

Repeat focussed echocardiography revealed a new prominent left to right shunt suggestive of VSD seen at the apical aneurysm (figure 6 and video 3). She was immediately transferred to the local cardiothoracic unit where she underwent a successful VSD repair the same day.

\section{OUTCOME AND FOLLOW-UP}

She is now well NYHA class 1 .

\section{DISCUSSION}

Ventricular septal rupture is a rare complication of acute myocardial infarction which if missed carries a poor mortality. In

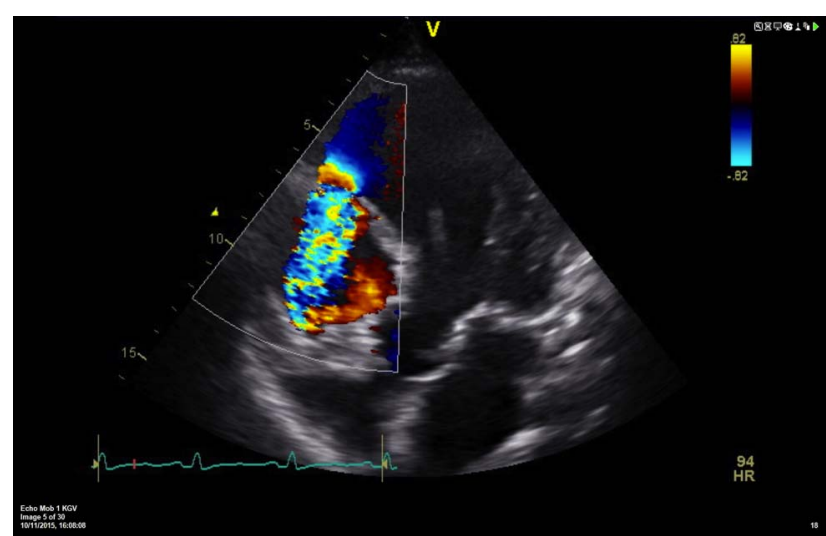

Figure 6 Repeat echocardiography showing a new prominent left to right shunt suggestive of VSD seen at the apical aneurysm with colour flow Doppler (apical five-chamber view).

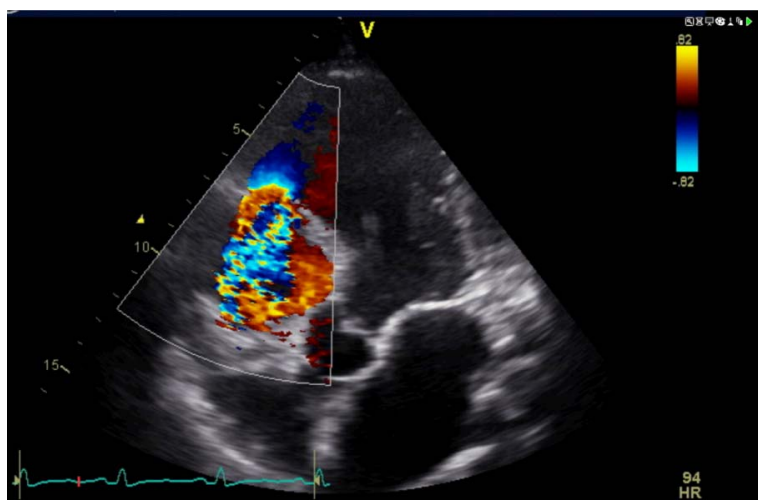

Video 3 Repeat echocardiography showing a new prominent left to right shunt suggestive of VSD seen at the apical aneurysm with colour flow Doppler (apical five-chamber view).

the pre-thrombolysis era, ventricular septal rupture complicated $1-3 \%$ of all acute myocardial infarctions. ${ }^{2}$ However, since the introduction of reperfusion therapy, the incidence of ventricular septal rupture has decreased complicating $0.17-0.31 \%$ of acute myocardial infarctions. ${ }^{3}$ Despite a reduction in incidence, the mortality of patients with ventricular septal rupture remains high (41-80\% in patients who have undergone PCI). ${ }^{3-6}$

Our patient presented to us for the second time 35 days postacute myocardial infarction. It is extremely rare for ventricular septal rupture to present with such a delayed onset. Thus, on admission, ventricular septal rupture was not included in the differential diagnosis. Typically, ventricular septal rupture occurs 3-5 days post-myocardial infarction. Recently, the SHOCK registry and APEX AMI trial have shown the time to identification of ventricular septal rupture to be much shorter at 16 and 7.7 hours, respectively. ${ }^{6} 7$

In retrospect, our patient had many of the known risk factors for developing a ventricular septal rupture including advancing age, female gender and also the culprit artery in this case was an occluded LAD. ${ }^{8}$ It is most likely that the patient suffered a type 3 ventricular septal rupture characterised by thinning of the interventricular septum and aneurysm formation postmyocardial infarction resulting in rupture of the septal wall. Type 1 ruptures are characterised by an abrupt slit-like tear in the interventricular septum acutely post-myocardial infarction 
( $<24$ hours), whereas type 2 ruptures are due to slowly progressing tears. ${ }^{3} 9$

Many patients with ventricular septal rupture present acutely with cardiogenic shock as in this case. Mechanical support systems such as intra-aortic balloon counter pulsation, extracorporeal membrane oxygenation systems or left ventricular assist devices are indicated as a bridge to further therapy. ${ }^{3} 10$ Immediate surgical repair is indicated in the haemodynamically unstable patient. Percutaneous closure may be considered if surgery is deemed to be too high risk or if the anatomy is amenable to device insertion. ${ }^{3}$

\section{Learning points}

- Patients representing within 6 weeks of acute myocardial infarction warrant repeat echocardiography to assess for new complications if there are new clinical findings.

- Ventricular septal rupture can present more than 1 month post-myocardial infarction.

- Ventricular septal rupture should be included in the differential diagnosis of patients presenting with cardiogenic shock.

- Delayed recognition and treatment of patients with haemodynamically unstable ventricular septal rupture carry a poor prognosis.

Contributors All authors were directly involved in the care of the patient. $R D, A H$ and MRJ drafted the manuscript. JA supervised the writing of the manuscript.
Competing interests None declared.

\section{Patient consent Obtained.}

Provenance and peer review Not commissioned; externally peer reviewed.

\section{REFERENCES}

1 Ba'albaki HA, Clements SD Jr. Left ventricular aneurysm: a review. Clin Cardiol 1989;12:5-13.

2 Birnbaum Y, Fishbein MC, Blanche $C$, et al. Ventricular septal rupture after acute myocardial infarction. N Engl J Med 2002;347:1426-32.

3 Jones BM, Kapadia SR, Smedira NG, et al. Ventricular septal rupture complicating acute myocardial infarction: a contemporary review. Eur Heart J 2014;35:2060-8.

4 Moreyra AE, Huang MS, Wilson AC, et al. Trends in incidence and mortality rates of ventricular septal rupture during acute myocardial infarction. Am J Cardiol 2010;106:1095-100.

5 López-Sendón J, Gurfinkel EP, Lopez de Sa E, et al. Factors related to heart rupture in acute coronary syndromes in the Global Registry of Acute Coronary Events. Eur Heart J 2010;31:1449-56.

6 French JK, Hellkamp AS, Armstrong PW, et al. Mechanical complications after percutaneous coronary intervention in ST-elevation myocardial infarction (from APEX-AMI). Am J Cardiol 2010;105:59-63.

7 Menon V, Webb JG, Hillis LD, et al. Outcome and profile of ventricular septal rupture with cardiogenic shock after myocardial infarction: a report from the SHOCK Trial Registry. SHould we emergently revascularize Occluded Coronaries in cardiogenic shock? J Am Coll Cardiol 2000;36(3 Suppl A):1110-16.

8 Crenshaw BS, Granger CB, Birnbaum Y, et al. Risk factors, angiographic patterns, and outcomes in patients with ventricular septal defect complicating acute myocardial infarction. GUSTO-I (Global Utilization of Streptokinase and TPA for Occluded Coronary Arteries) trial investigators. Circulation 2000;101:27-32.

9 Becker AE, van Mantgem JP. Cardiac tamponade. A study of 50 hearts. Eur J Cardiol 1975;3:349-58.

10 McMurray JJ, Adamopoulos S, Anker SD, et al. ESC guidelines for the diagnosis and treatment of acute and chronic heart failure 2012: the Task Force for the Diagnosis and Treatment of Acute and Chronic Heart Failure 2012 of the European Society of Cardiology. Developed in collaboration with the Heart Failure Association (HFA) of the ESC. Eur J Heart Fail 2012;14:803-69.

Copyright 2016 BMJ Publishing Group. All rights reserved. For permission to reuse any of this content visit

http://group.bmi.com/group/rights-licensing/permissions.

BMJ Case Report Fellows may re-use this article for personal use and teaching without any further permission.

Become a Fellow of BMJ Case Reports today and you can:

- Submit as many cases as you like

- Enjoy fast sympathetic peer review and rapid publication of accepted articles

- Access all the published articles

- Re-use any of the published material for personal use and teaching without further permission

For information on Institutional Fellowships contact consortiasales@bmjgroup.com

Visit casereports.bmj.com for more articles like this and to become a Fellow 